Research Article

\title{
Thermodynamic Characteristics of Methane Adsorption of Coal with Different Initial Gas Pressures at Different Temperatures
}

\author{
Tingting Cai $\mathbb{D}^{1},{ }^{1}$ Zengchao Feng $\mathbb{D}^{2},{ }^{2}$ Yulong Jiang $\mathbb{D}^{2}, 2$ and Dong Zhao $\mathbb{D}^{1}$ \\ ${ }^{1}$ College of Safety and Emergency Management Engineering, Taiyuan University of Technology, Taiyuan, Shanxi 030024, China \\ ${ }^{2}$ Key Laboratory of In-situ Property Improving Mining of Ministry of Education, Taiyuan University of Technology, Taiyuan, \\ Shanxi 030024, China
}

Correspondence should be addressed to Tingting Cai; caitingting@tyut.edu.cn

Received 21 December 2018; Revised 16 February 2019; Accepted 18 February 2019; Published 7 March 2019

Academic Editor: Claudio Pettinari

Copyright (C) 2019 Tingting Cai et al. This is an open access article distributed under the Creative Commons Attribution License, which permits unrestricted use, distribution, and reproduction in any medium, provided the original work is properly cited.

The adsorption of methane in coal depends on both pressure and temperature, and the adsorption gas content decreases as the temperature rises while increases as the pressure increases. When the gas molecule switches between the free state and adsorbed state, energy exchange is accompanied. To study the thermodynamic characteristics (adsorption heat, adsorption content, and adsorption time) of the methane adsorption of coal, the isothermal methane adsorption experiments of coal with different initial free gas pressures at different temperatures $\left(30-90^{\circ} \mathrm{C}\right)$ were conducted. In this paper, a well-defined mathematical function of the adsorption heat was established on the basis of the actual gas state equation, Boltzmann energy distribution theory, and the twostate energy model, and the function was verified by the experimental data. The results show that the mathematical function of the adsorption heat can well describe the relationship among the adsorption heat, temperature, and initial free gas pressure in the closed adsorption system, and the adsorption heat involves the initial free gas pressure. The greater the initial free gas pressure, the less the adsorption heat is. In the adsorption process with different initial free gas pressures at different temperatures, the real-time free gas content increases with time and the adsorption system shows desorption process generally. For the adsorption process with the same initial free gas pressure, the adsorption time increases with the rising temperature. For the adsorption process with different initial free gas pressures at the same temperature, the greater the initial free gas pressure, the shorter the adsorption time it takes to reach an equilibrium state. The results help to understand the thermodynamic characteristics and the heat and mass transfer of methane in coal adsorption.

\section{Introduction}

In recent years, coalbed methane $(\mathrm{CBM})$ has become a potential alternative energy to fossil fuels for its clean property, high calorific value, and large storage [1]. Coal is a stable absorbent; as a natural reservoir, it has a great gas adsorption capacity. Many theoretical and experimental studies on the adsorption gas content of coal have been reported [2-4]. For example, Lu et al. [5] performed the isothermal methane adsorption experiments and studied the supercritical methane adsorption characteristics of middlerank tectonically deformed coals (TDCs) from the Huaibei coalfield, and the mechanism of methane adsorption in
TDCs was explored. Liu et al. [6] investigated the effect of temperature on methane adsorption capacity and adsorbed methane density for different size pores based on the grand canonical Monte Carlo (GCMC) simulation. They also performed methane adsorption experiments, and the experimental data were directly validated to numerical model. Feng et al. [7] prepared three different types of coal samples (lean coal, anthracite, and coke coal) for adsorption experiments with methane and nitrogen at temperatures between $30^{\circ} \mathrm{C}$ and $240^{\circ} \mathrm{C}$ and established a new mathematical model to forecast the gas adsorption capacities of coal at any temperature and pressure. Li et al. [8] and Zhao et al. [9] studied the impact of temperature on the parameters in 
Langmuir equation, but they failed to obtain an improved Langmuir equation to precisely describe the effect of temperature or pressure variation on adsorption capacity. In addition, many studies have been reported to discuss the adsorption capacity and thermodynamic characteristics of coal from the view of energy, such as the surface free energy variation $[10,11]$ and isosteric heat [12-16]. For example, $[17,18]$ demonstrated the adsorption heat of coal on methane ranging $4-9 \mathrm{~kJ} / \mathrm{mol}$ by molecular simulation. Tang et al. [19] obtained the mean isosteric heats of methane on anthracite, lean coal, and gas-fat coal as $23.31 \mathrm{~kJ} / \mathrm{mol}$, $20.47 \mathrm{~kJ} / \mathrm{mol}$, and $11.14 \mathrm{~kJ} / \mathrm{mol}$, respectively, on the basis of the experimental results of isothermal tests from 243.15 to $303.15 \mathrm{~K}$. Zhou et al. [20] processed the isothermal adsorption test data at $298.15 \mathrm{~K}, 303.15 \mathrm{~K}$, and $313.15 \mathrm{~K}$ conditions and obtained the initial isosteric heats of methane on coal to be $33.4 \mathrm{~kJ} / \mathrm{mol}$. Generally, the adsorption heat ranges from 0 to $30 \mathrm{~kJ} / \mathrm{mol}$ [21]. However, only the adsorption heat value is not sufficient to fully understand the adsorption mechanism of coalbed methane. The thermodynamic characteristics of CBM adsorption, such as adsorption time and adsorption rate, are also notably important for understanding the heat and mass transfer mechanism of CBM in coal seams, while few studies have been reported.

On the contrary, in most isothermal adsorption experiments of coal, coal powders with mesh number of $60 \sim 80$ are often used [22]. Actually, in the thermal exploitation of coalbed methane (CBM), gas and vapor immigrate along pores and fractures. Coal is a highly developed porous material; however, in coal powders, the original macropores and visible fractures are damaged, which impact the coalspecific surface area and the paths for gas immigration a lot, resulting in great adsorption difference between raw coal and coal powders. The adsorption data on large-scale coal samples instead of coal powders is much closer to the engineering practice because of the great amount of remaining original pores and fractures.

In view of the above gaps, a series of isothermal adsorption experiments with different initial free gas content at different temperatures on raw coal were conducted in this paper. Moreover, a mathematic expression of the adsorption heat, temperature, and gas pressure was established through a two-energy-state model of methane to describe the methane adsorption process of coal, and then the experimental data were used to verify the above expression. Furthermore, the adsorption rate and adsorption time at different temperatures were analyzed. The results of this paper help understand the energy transform and the effect of temperature, gas pressure on the heat, and mass transfer in methane adsorption of coal.

\section{Experiments}

2.1. Experimental Samples. The samples are raw lean coal taken from the 9 \# coal seam at the buried depth of $400 \mathrm{~m}$ in Gucheng mine and the 5\# coal seam at the buried depth of $200 \mathrm{~m}$ in Gaohe mine, respectively, in the Qinshui coalfield in North China. Raw lean coal was machined into cylindrical core samples with a size of $\phi 100 \mathrm{~mm} \times 150 \mathrm{~mm}$ as can be seen in Figure 1. Both the coal samples were machined vertically to beddings in coal, and there were no visible fractures on the coal sample surface. The samples were numbered as \#1 and \#2, respectively, and then, the coal samples treated at the temperature of $90^{\circ} \mathrm{C}$ were drying before the isothermal adsorption experiments were conducted.

The proximate analysis, porosity, and vitrinite reflectance results of the coal samples are shown in Table 1. In this paper, the coal samples with the same identical degree of metamorphism were chosen for mutual verification.

2.2. Experimental System. The experimental system used for the isothermal adsorption experiments of coal is shown in Figure 2. The main experimental equipment includes the adsorption instrument, high-temperature heater, and GW$1200 \mathrm{~A}$ temperature controller. The dry coal sample is put in the adsorption instrument. The adsorption instrument is made of the 304 stainless steel, and it has a good thermal conductivity. The aerodynamic circulation heating is used in the precise heater to heat the coal sample in the adsorption instrument to the preset temperature, and the maximum heating temperature is $600^{\circ} \mathrm{C}$. The precise heater is closed and has a good sealing performance with little heat exchange with the outside. The thermocouple thermometer sensor and automatic temperature-control sensor are set in the adsorption instrument. The temperature in the adsorption instrument is measured by the thermocouple thermometer in real time, and the temperature rise and control is conducted by the high-sensitivity temperature controller with temperature control precision $\pm 0.1^{\circ} \mathrm{C}$. In addition, there are also some auxiliary experiment devices, such as the precise digital pressure gauge, vacuum pump, gas storage cylinder, and gas collection equipment. The accuracy of the precise digital pressure gauge is $0.001 \mathrm{MPa}$, and it can record and store the real-time free gas pressure inside the adsorption instrument in the entire experimental process. The gas collection equipment is used for gas exhaust. In order to ensure that the exhausted methane gas volume is equivalent each time, the graduated cylinder with the measurement range of $1 \mathrm{~L}$ and the least calibrations of $10 \mathrm{~mL}$ was used to drain water when collecting free methane gas. The entire experimental system is placed in a $20^{\circ} \mathrm{C}$ thermostatic room with a temperature change of $\pm 1^{\circ} \mathrm{C}$.

2.3. Isothermal Adsorption Experiments. Once the experimental system was assembled and fixed, a series of isothermal methane adsorption experiments of coal at different temperatures were conducted. The experimental steps can be divided into three stages. The first stage dealt with the system air tightness using high-pressure helium. The vacuum pump was taken on to degas the free methane gas in the adsorption instrument and the gas inside the coal. After $48 \mathrm{~h}$ of treatment, the vacuum pump was taken off when the vacuum degree was lower than $0.05 \mathrm{~Pa}$, and the methane gas storage cylinder was open to inject gas to a 


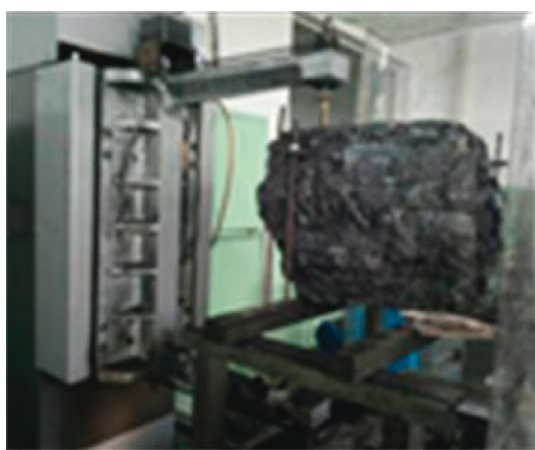

(a)
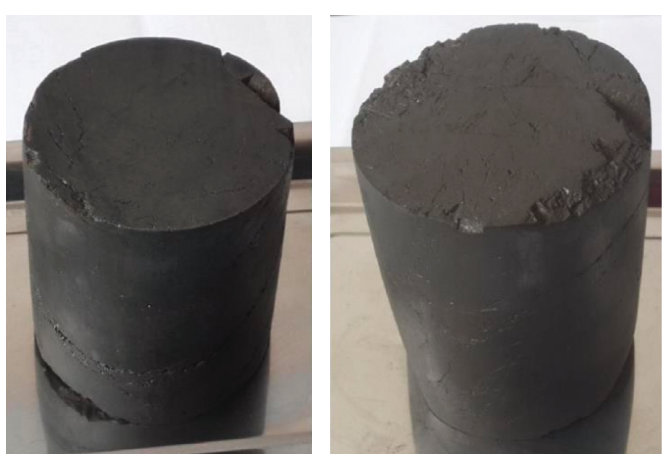

(b)

FIgURE 1: Experimental samples preparation.

TABle 1: Proximate analysis, porosity, and vitrinite reflectance of the coal samples.

\begin{tabular}{lcccccc}
\hline Coal sample & $R_{\text {o,max }}$ & $\begin{array}{c}\text { Porosity } \\
(\%)\end{array}$ & $\begin{array}{c}M_{\mathrm{ad}} \\
(\%)\end{array}$ & $\begin{array}{c}A_{\mathrm{d}} \\
(\%)\end{array}$ & \multicolumn{2}{c}{ matter } \\
& & & & & $(\%)$ & $V_{\text {ad }}$ \\
$(\%)$
\end{tabular}

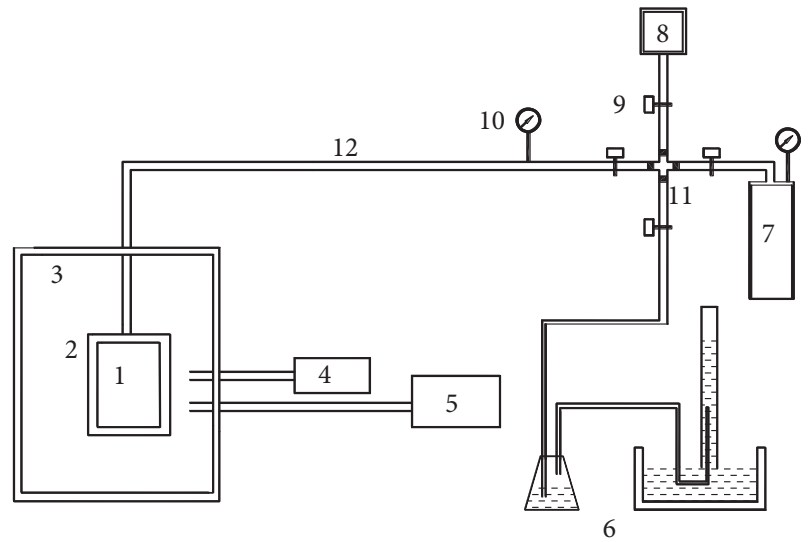

Figure 2: Experimental system. (1) Coal sample, (2) adsorption instrument, (3) high-temperature heater, (4) thermocouple thermometer, (5) GW-1200A temperature controller, (6) gas collection device, (7) gas storage cylinder, (8) vacuum pump, (9) valve, (10) digital pressure gauge with precision $\pm 1.0 \mathrm{kPa}$, (11) connections, and (12) pipings.

certain volume. In the second stage, the isothermal adsorption experiments were conducted. In these experiments, seven temperatures were set, ranging from 30 to $90^{\circ} \mathrm{C}$ at an interval of $10^{\circ} \mathrm{C}$. The precise digital pressure gauge was used throughout the experiments to record the real-time pressure of the free gas inside the adsorption instrument. When the reading of the gauge was quite stable and a change of no more than $0.002 \mathrm{MPa}$ was recorded over a 20 min period, the adsorption process was considered to have reached an equilibrium state, and the final pressure was recorded. It took about 6 hours for each adsorption balance to be achieved before the temperature controller was fixed to the next temperature. In the third stage, once the adsorption balance at $90^{\circ} \mathrm{C}$ had been reached, the instrument was naturally cooled to room temperature $20^{\circ} \mathrm{C}$ and the gas collection equipment used to drain water for collecting methane gas was open to exhaust gas of a certain volume and to change the free gas pressure in the adsorption instrument. Consequently, the different initial free gas content conditions were achieved. Then, the isothermal adsorption experiments at temperatures ranging between $30^{\circ} \mathrm{C}$ and $90^{\circ} \mathrm{C}$ in the second stage were then repeated at the new gas pressure. These steps were repeated six times with the exhausted free methane gas volume constant at each time [23]. The test scheme is shown in Table 2. The initial injection gas content in the two samples was $18 \mathrm{~L}$ and $30 \mathrm{~L}$, and the initial free gas pressures were $1.145 \mathrm{MPa}$ and $1.595 \mathrm{MPa}$, respectively.

\section{Results}

3.1. Adsorption Heat. The adsorption heat of methane adsorption of coal reflects the energy change of methane molecule in the process of adsorption or desorption, which is a thermodynamic interaction between the methane molecule and coal surface. The methane adsorption of coal is a typical physical adsorption, and it can be drawn as follows:

free methane molecule $\rightleftharpoons$ adsorbed methane molecule;

$$
\Delta H=\varepsilon<0,
$$

where $\Delta H$ is the thermodynamic enthalpy and $\varepsilon$ is the adsorption heat of each methane molecular released when switching from the free state to adsorbed state.

From equation (1), it can be seen the methane adsorption of coal is exothermic and the methane desorption of coal is endothermic. According to the real gas state equation, when gas adsorption/desorption equilibrium is reached in a closed system, the thermodynamic state of the free gas in the system can be drawn as follows:

$$
P V=n R T Z,
$$

where $P$ is the equilibrium free gas pressure, $\mathrm{MPa}$; $V$ is the volume of free gas, $\mathrm{L} ; n$ is the quantity of the free gas, mol; $R$ 
TABLE 2: The test scheme.

\begin{tabular}{lccc}
\hline Samples & $\begin{array}{c}\text { Free gas pressure } \\
(\mathrm{MPa})\end{array}$ & $\begin{array}{c}\text { Free gas content } \\
(\mathrm{L})\end{array}$ & $\begin{array}{c}\text { Temperature } \\
\left({ }^{\circ} \mathrm{C}\right)\end{array}$ \\
\hline \multirow{4}{*}{$\# 1$} & $P_{1}$ & $V_{1}$ & $30,40, \ldots, 90$ \\
& $P_{2}=P_{1}-\Delta P$ & $V_{2}=V_{1}-\Delta V$ & $30,40, \ldots, 90$ \\
& $P_{3}=P_{2}-\Delta P$ & $V_{3}=V_{2}-\Delta V$ & $30,40, \ldots, 90$ \\
$\# 2$ & $P_{4}=P_{3}-\Delta P$ & $V_{4}=V_{3}-\Delta V$ & $30,40, \ldots, 90$ \\
& $P_{5}=P_{4}-\Delta P$ & $V_{5}=V_{4}-\Delta V$ & $30,40, \ldots, 90$ \\
& $P_{6}=P_{5}-\Delta P$ & $V_{6}=V_{5}-\Delta V$ & $30,40, \ldots, 90$ \\
\hline
\end{tabular}

is the gas constant, $8.3145 \mathrm{~J} /(\mathrm{mol} \cdot \mathrm{K})$; $T$ is the gas temperature, $\mathrm{K}$; and $Z$ is the compressibility coefficient of gas, and it involves with temperature and gas pressure.

In a closed adsorption system, there are methane molecules in either the free state or adsorbed state. It is assumed that the minimum energy that an adsorbed molecular required to escape from the coal surface and switch into the free state was $\varepsilon_{0}$, so the methane molecules can be simply divided into two parts, that is, the methane molecules with energy greater than $\varepsilon_{0}$ are in the free state, and the methane molecules with energy less than $\varepsilon_{0}$ are in adsorbed state. This is the two-energy state model of methane distribution in a gas adsorption system [7,21]. When the balance of the gas adsorption is reached, the distribution of all the methane molecules in the system can be defined according to the Boltzmann energy distribution law. Therefore, the number of molecules in the free state can be simplified and calculated as follows:

$$
N=A e^{-\left(\varepsilon_{0} / k T\right)},
$$

where $N$ is the number of free gas molecules, $A$ is a ratio constant, and $k$ is the Boltzmann coefficient, $1.38 \times 10^{-23} \mathrm{~J} / \mathrm{K}$.

The quantity of the free gas can be written as

$$
n=\frac{N}{N_{\mathrm{a}}},
$$

where $N_{\mathrm{a}}$ is the Avogadro constant.

Substituting equations (3) and (4) into equation (2), and we can get

$$
P=B T e^{-\left(\varepsilon_{0} / k T\right)}
$$

where $B$ is a coefficient and it can be written as $B=A R Z / V N_{\mathrm{a}}$.

The above equation can be transformed into an expression of the adsorption heat as follows:

$$
\varepsilon=-k T \ln \left(\frac{P}{B T}\right)
$$

where $\varepsilon$ is the adsorption heat.

From the above equation, it can be seen that the adsorption heat is a function of gas pressure and temperature, and both temperature and pressure affect the adsorption heat.

As the real-time pressure of free gas inside the adsorption instrument was recorded by the precise digital pressure gauge throughout the experiments, the equilibrium pressures in the closed system with different initial free gas content at different temperatures are shown in Figure 3; as can be seen, for each equilibrium pressure curve with different initial free gas content, the equilibrium pressure increases with the rising temperatures. At the same temperature gradient, the equilibrium pressure increases nonlinearly. Specifically, the equilibrium pressure increases smoothly and slowly in low-temperature range, while it presents a quick increase in high-temperature range. In addition, such nonlinear increase trend is much more significant for equilibrium pressures with more free gas content, and it is not much obvious for the equilibrium pressures with less free gas content. Generally, the equilibrium pressure curves of the free gas in a closed system and temperature are in a good nonlinear relationship.

As shown in equation (6), the adsorption heat is a mathematic function of both pressure and temperature, and equation (5) is suitable to describe the relationship among adsorption heat, temperature, and equilibrium pressure of free gas, so equation (5) is used to fit the curves in Figure 3, and the results are shown in Table 3 .

In Table 3, it can be seen the correlation coefficients of the fitting results approach to 1 , which indicates equation (5) derived on the basis of the actual gas state equation, Boltzmann energy distribution theory, and two-state energy model can well describe the relationship among the adsorption heat, equilibrium pressure, and temperature in isothermal methane adsorption at different temperatures.

In addition, comparing the adsorption heat values at different equilibrium initial free gas pressures, it can be seen that the adsorption heat involves initial equilibrium conditions, specifically, the greater the initial equilibrium pressure, the smaller the adsorption heat. It suggests that in a closed adsorption system, the greater the initial free gas pressure, the less the adsorption heat released for the free gas to reach adsorption balance. Therefore, it can be inferred that at the same temperature gradient, the adsorption process with greater initial free gas pressure is prone to reach balance more quickly.

3.2. Adsorption Content. According to the final equilibrium pressure at each adsorption balance, the actual gas state equation, and the Langmuir adsorption theory [24, 25], the methane adsorption content (absorbed methane volume per mass of coal, $\mathrm{cm}^{3} / \mathrm{g}$ ) with different initial free gas content at different temperatures was calculated as follows:

$$
Q_{\mathrm{a}}=\frac{a b P_{\mathrm{e}}}{1+b P_{\mathrm{e}}},
$$

where $Q_{\mathrm{a}}$ is the methane adsorption content, $\mathrm{cm}^{3} / \mathrm{g}, P_{\mathrm{e}}$ is the equilibrium pressure, $\mathrm{MPa}, a$ is the adsorption constant, $\mathrm{cm}^{3} / \mathrm{g}$, and $b$ is the adsorption constant, $\mathrm{MPa}^{-1}$. The constants $a$ and $b$ can be determined by the isothermal adsorption experiments.

The methane adsorption content curves with different initial free gas content at different temperatures are shown in Figure 4. As can be seen, the methane adsorption 


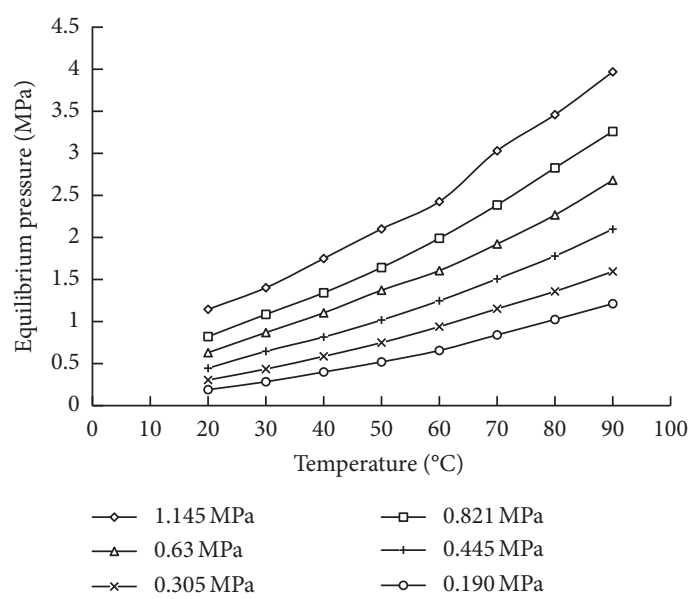

(a)

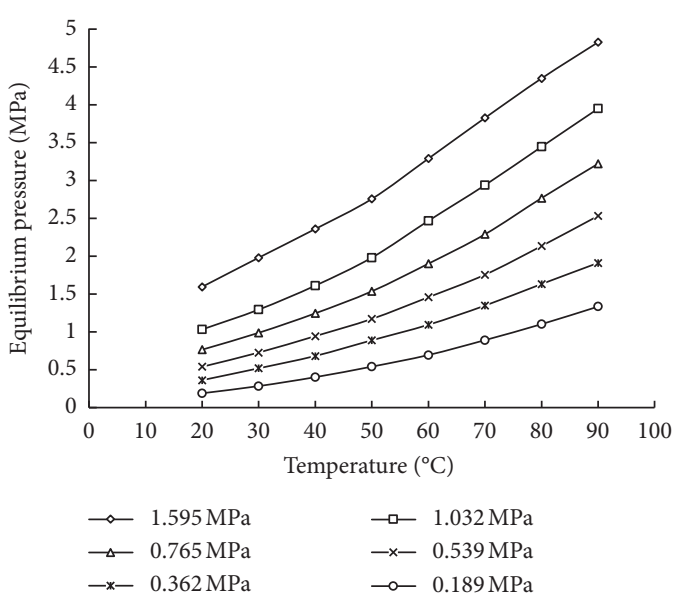

(b)

FIgUre 3: The Equilibrium pressure with different initial free gas content at different temperatures. (a) \#1 coal; (b) \#2 coal.

TABle 3: Fitting results of equation (5).

\begin{tabular}{cccccc}
\hline Coal & Initial equilibrium free gas pressure $(\mathrm{MPa})$ & Fitting results & Adsorption heat $(\varepsilon)$ & $B$ & Correlation coefficient \\
\hline & 1.145 & $P=1.1664 T e^{-1580.2 / T}$ & 1580.2 & 1.1664 & 0.9980 \\
& 0.821 & $P=1.1533 T e^{-1754.9 / T}$ & 1754.9 & 1.1533 & 0.9983 \\
\#1 & 0.630 & $P=1.0970 T e^{-1808.3 / T}$ & 1808.3 & 1.0970 & 0.9930 \\
& 0.445 & $P=1.3371 T e^{-1963.8 / T}$ & 1963.8 & 1.3371 & 0.9919 \\
& 0.305 & $P=1.8109 T e^{-2165.1 / T}$ & 2165.1 & 1.8109 & 0.9918 \\
\hline & 0.190 & $P=3.1230 T e^{-2460.3 / T}$ & 2460.3 & 3.1230 & 0.9922 \\
\hline & 1.595 & $P=1.6928 T e^{-1367.4 / T}$ & 1367.4 & 1.6928 & 0.9974 \\
& 1.032 & $P=1.3753 T e^{-1747.6 / T}$ & 1747.6 & 1.3753 & 0.9986 \\
& 0.765 & $P=1.5371 T e^{-1866.0 / T}$ & 1866.0 & 1.5371 & 0.9997 \\
& 0.539 & $P=1.7566 T e^{-2000.9 / T}$ & 2000.9 & 1.7566 & 0.9984 \\
& 0.362 & $P=2.210 T e^{-2175.3 / T}$ & 2175.3 & 2.2102 & 0.9942 \\
& 0.189 & $P=5.2735 T e^{-2618.2 / T}$ & 2618.2 & 5.2735 & 0.9944 \\
\hline
\end{tabular}

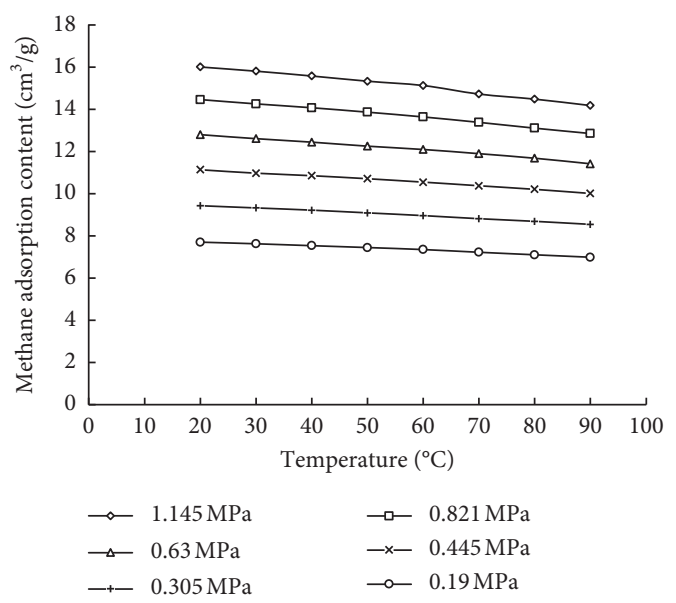

(a)

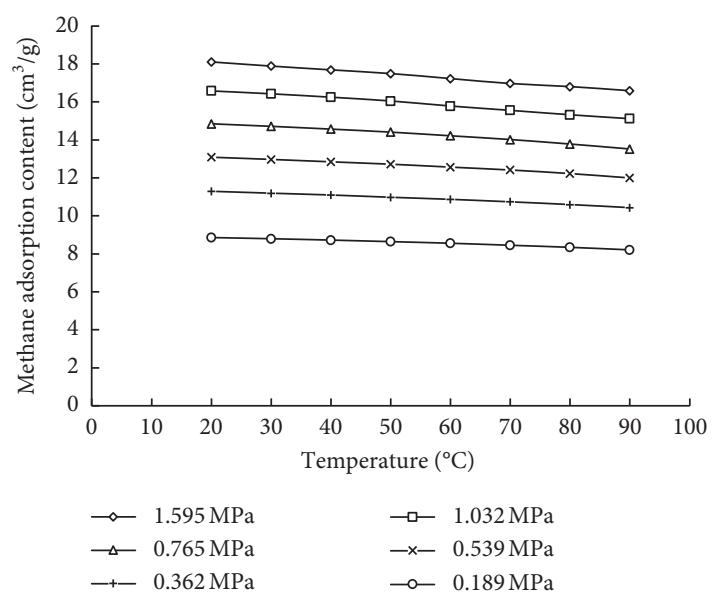

(b)

FIGURE 4: Methane adsorption content with different initial free gas content at different temperatures. (a) \#1 coal sample (b) \#2 coal sample.

content decreases linearly with the rising temperature, which indicates as the temperature rises, more desorbed methane gas get free and the system shows a desorption process generally. The rising temperature is in favor of desorption.
3.3. Adsorption Time. As the real-time pressure of the free gas inside the adsorption instrument was recorded by the precise digital pressure gauge throughout the experiments, the real-time free gas mass in the adsorption instrument $n$ can be calculated on the basis of the actual gas state equation (equation (2)), 


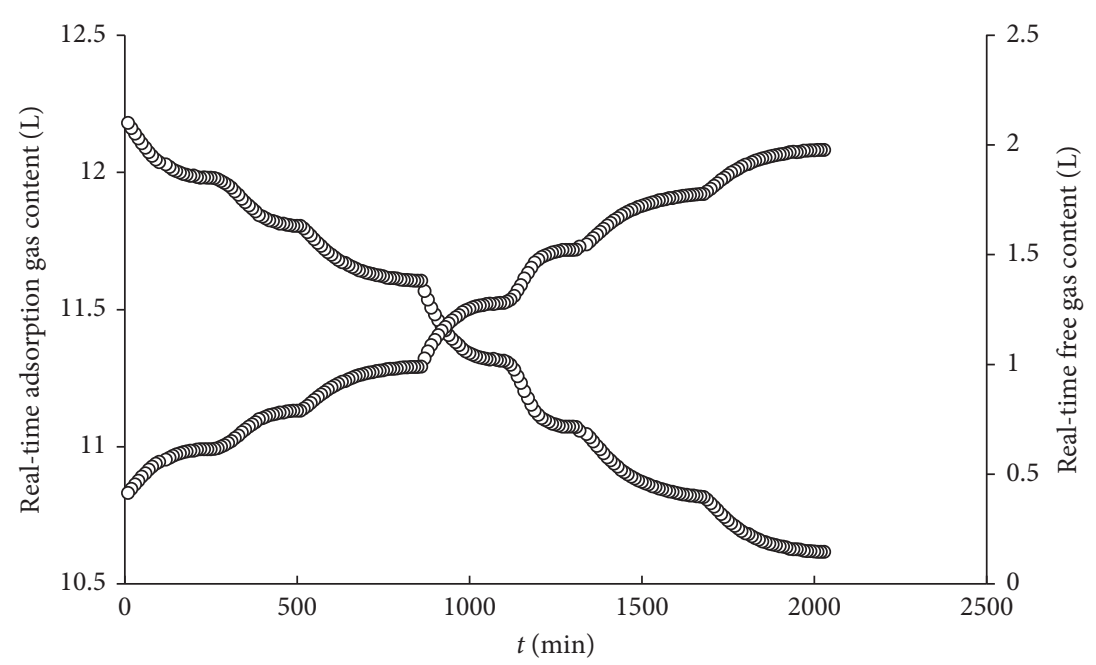

(a)

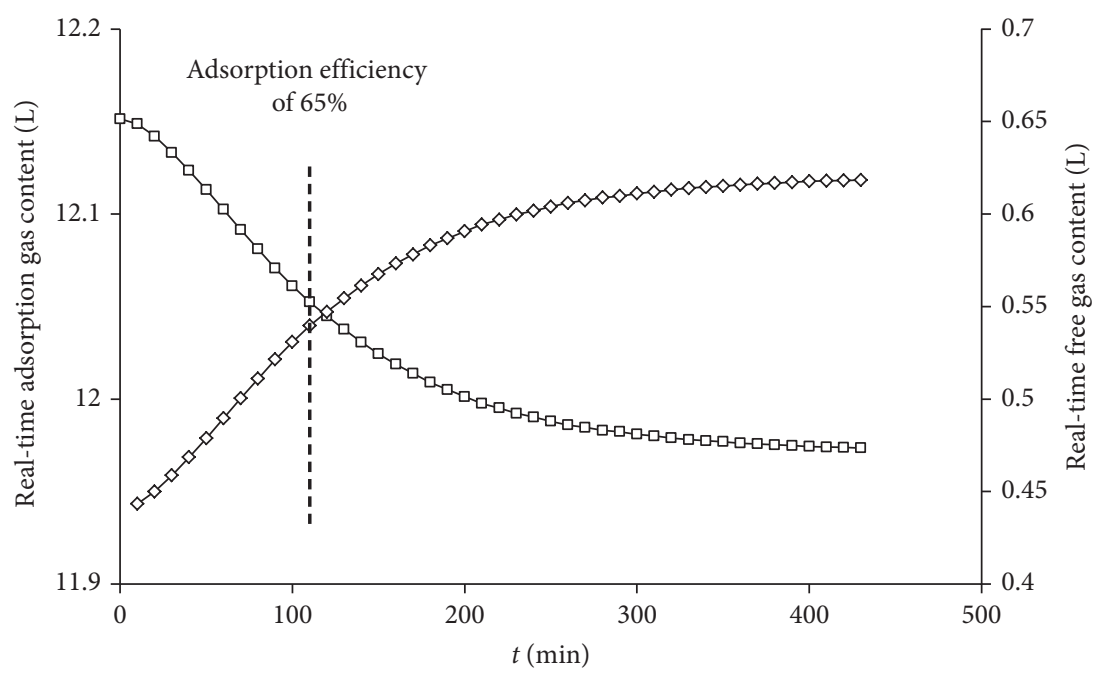

(b)

FiguRE 5: Real-time free gas and adsorption gas content evolution curves in the adsorption system of \# 1 coal with the initial free gas pressure of $0.445 \mathrm{MPa}$. (a) Real-time free gas and adsorption gas content evolution curves $\left(V_{\mathrm{f}}, V_{\mathrm{a}}\right)$ of \#1 coal with the initial free gas pressure of $0.445 \mathrm{MPa}$ at different temperatures. (b) Real-time free gas and adsorption gas content evolution curves $\left(V_{\mathrm{f}}^{30^{\circ} \mathrm{C}}, V_{\mathrm{a}}^{30^{\circ} \mathrm{C}}\right)$ of $\# 1$ coal with the initial free gas pressure of $0.445 \mathrm{MPa}$ at $30^{\circ} \mathrm{C}$.

$$
n=\frac{P V}{R T Z}
$$

And then, the real-time free gas content $V_{\mathrm{f}}$ can be obtained.

$$
V_{\mathrm{f}}=n \cdot V_{\mathrm{m}} \text {, }
$$

where $V_{\mathrm{m}}$ is the molar volume of gas at the temperature of $25^{\circ} \mathrm{C}$ and under the gas pressure of $101.325 \mathrm{kPa}$, and it can be calculated by the following equation:

$$
\begin{aligned}
V_{\mathrm{m}} & =8.3145 \mathrm{~J} /(\mathrm{mol} \cdot \mathrm{K}) \times 293.15 \mathrm{~K} / 101.325 \mathrm{kPa} \\
& =24.466 \mathrm{~L} / \mathrm{mol} .
\end{aligned}
$$

In addition, as the initial injection gas content and exhausted gas content each time are known, the real-time methane adsorption content $V_{\mathrm{a}}$ can be calculated as follows:

$$
V_{\mathrm{a}}=V-V_{\mathrm{f}},
$$

where $V_{\mathrm{a}}$ is the real-time methane adsorption content, $L$, and $V$ is the initial methane content, $L$.

The adsorption methane content of coal sample \#1 with the initial free gas pressure of $0.445 \mathrm{MPa}$ as the temperature rises from $20^{\circ} \mathrm{C}$ to $90^{\circ} \mathrm{C}$ was taken as an example, and Figure 5(a) shows the real-time free gas content $\left(V_{\mathrm{f}}\right)$ and the real-time methane adsorption content $\left(V_{\mathrm{a}}\right)$ evolution curves, in which seven adsorption phases were sectioned by temperatures. Specifically, the real-time free gas volume $\left(V_{\mathrm{f}}^{30^{\circ} \mathrm{C}}\right)$ evolution curve and the real-time adsorption gas content $\left(V_{\mathrm{a}}^{30^{\circ} \mathrm{C}}\right)$ evolution in the adsorption system at constant temperature of $30^{\circ} \mathrm{C}$ are shown in Figure 5(b).

As can be seen in Figure 5(b), when the temperature was constant in the system, the cumulative free gas volume in the adsorption system increases gradually and then 
finally stabilized, reaching an equilibrium state, while the real-time adsorption gas content decreases at a transient speed and then eventually stabilized at a dead slow speed. Generally, the real-time free gas content increases with time, and the adsorption system shows a desorption process. In Figure 5(a), as the temperatures rises from $30^{\circ} \mathrm{C}$ to $90^{\circ} \mathrm{C}$, the real-time free gas content evolution in the adsorption system at each constant temperature is similar. Specifically, the cumulative free gas volume increases and the cumulative adsorption gas volume decreases gradually. In a word, as the temperature rises, more adsorbed gas get free.

In the thermal exploitation of coalbed methane (CBM), the desorption efficiency and desorption time are two significant dynamic parameters to evaluate the exploitation speed. In engineering practice, desorption time is usually defined as the cumulative time when desorption efficiency reaches $65 \%$. In the isothermal adsorption experiments in this paper, as the real-time adsorption gas content decreases gradually while the real-time free gas volume increases gradually, the adsorption system shows a desorption process generally, so the isothermal adsorption experiments at the different increasing temperatures can be taken as desorption processes at different temperatures, and then the corresponding adsorption time can be calculated on the basis of the experimental data similarly. Specifically, for each realtime adsorption gas volume evolution curve, when the adsorption efficiency reaches $65 \%$, the time it takes is considered as the adsorption time, as can be seen in Figure 5(b). The adsorption time of each adsorption process with different initial free gas pressures at different temperatures were calculated and are shown in Tables 4 and 5.

As can be seen in Tables 4 and 5, for the adsorption processes with the same initial gas pressure, the adsorption time calculated varies at different temperatures; specifically, the adsorption time increases with rising temperature. On the one hand, at higher temperature, the adsorbed methane gas is less than that at lower temperature, so it is harder for methane to desorb at high temperature. On the other hand, the adsorption promotion from free gas pressure in the adsorption system to inhibit desorption still exists, and the greater the gas pressure, the smaller adsorption promotion; therefore, it takes more time for the adsorption system to get into the equilibrium state.

Comparing the adsorption time at each temperature with different initial free gas pressures, it can be seen that the adsorption time and the initial free gas pressures are in a close negative correlation no matter at low temperature $\left(30,40^{\circ} \mathrm{C}\right)$ or high temperature $\left(80,90^{\circ} \mathrm{C}\right)$. Specifically, the greater the initial free gas pressure, the shorter the adsorption time it takes to reach an equilibrium state. It is because the adsorption heat is smaller when the initial free gas pressure is greater, which indicates that the less heat is relieved in the closed adsorption system to reach the adsorption balance. At the same temperature intervals, it takes shorter time for the free gas to reach the adsorption balance; correspondingly, the adsorption time at each constant temperature is short, too, which is coherent with the former analysis.
TABle 4: Adsorption time of \#1 coal sample.

\begin{tabular}{|c|c|c|}
\hline $\begin{array}{l}\text { Initial free gas } \\
\text { pressure (MPa) }\end{array}$ & Temperature $\left({ }^{\circ} \mathrm{C}\right)$ & Adsorption time (min) \\
\hline \multirow{7}{*}{1.145} & 30 & 101.7 \\
\hline & 40 & 111.9 \\
\hline & 50 & 118.7 \\
\hline & 60 & 119.1 \\
\hline & 70 & 126.7 \\
\hline & 80 & 138.4 \\
\hline & 90 & 145.6 \\
\hline \multirow{7}{*}{0.821} & 30 & 107.3 \\
\hline & 40 & 110.7 \\
\hline & 50 & 120.2 \\
\hline & 60 & 123.4 \\
\hline & 70 & 132.5 \\
\hline & 80 & 148.3 \\
\hline & 90 & 144.1 \\
\hline \multirow{7}{*}{0.630} & 30 & 109.9 \\
\hline & 40 & 115.4 \\
\hline & 50 & 123.3 \\
\hline & 60 & 121.4 \\
\hline & 70 & 144.6 \\
\hline & 80 & 139.8 \\
\hline & 90 & 153.8 \\
\hline \multirow{7}{*}{0.445} & 30 & 110.1 \\
\hline & 40 & 92.2 \\
\hline & 50 & 96.4 \\
\hline & 60 & 104.2 \\
\hline & 70 & 118.8 \\
\hline & 80 & 113.6 \\
\hline & 90 & 130.8 \\
\hline \multirow{7}{*}{0.305} & 30 & 115.4 \\
\hline & 40 & 120.2 \\
\hline & 50 & 125.6 \\
\hline & 60 & 137.4 \\
\hline & 70 & 136.3 \\
\hline & 80 & 148.6 \\
\hline & 90 & 159.0 \\
\hline \multirow{7}{*}{0.190} & 30 & 122.5 \\
\hline & 40 & 130.6 \\
\hline & 50 & 131.0 \\
\hline & 60 & 133.0 \\
\hline & 70 & 141.4 \\
\hline & 80 & 153.7 \\
\hline & 90 & 163.8 \\
\hline
\end{tabular}

\section{Conclusions}

In this paper, the isothermal methane adsorption experiments of coal with different initial free gas contents at different temperatures were conducted, and the thermodynamic characteristics (adsorption heat, adsorption content, and adsorption time) were studied. The main conclusions are as follows:

(1) In a closed adsorption system, when the free gas reaches an equilibrium state, the relationship among the adsorption heat, temperature, and initial free gas pressure can be expressed in a well-defined mathematical function established on the basis of the actual gas state equation, Boltzmann energy distribution 
TABLE 5: Desorption time of \#2 coal sample.

\begin{tabular}{|c|c|c|}
\hline $\begin{array}{l}\text { Initial free gas } \\
\text { pressure }(\mathrm{MPa})\end{array}$ & Temperature $\left({ }^{\circ} \mathrm{C}\right)$ & Adsorption time ( $\mathrm{min}$ ) \\
\hline \multirow{7}{*}{1.595} & 30 & 121.6 \\
\hline & 40 & 117.2 \\
\hline & 50 & 119.4 \\
\hline & 60 & 130.0 \\
\hline & 70 & 142.4 \\
\hline & 80 & 148.9 \\
\hline & 90 & 152.6 \\
\hline \multirow{7}{*}{1.032} & 30 & 121.2 \\
\hline & 40 & 117.5 \\
\hline & 50 & 128.2 \\
\hline & 60 & 145.8 \\
\hline & 70 & 135.5 \\
\hline & 80 & 147.8 \\
\hline & 90 & 152.4 \\
\hline \multirow{7}{*}{0.765} & 30 & 120.8 \\
\hline & 40 & 125.5 \\
\hline & 50 & 134.2 \\
\hline & 60 & 137.4 \\
\hline & 70 & 148.2 \\
\hline & 80 & 152.7 \\
\hline & 90 & 158.5 \\
\hline \multirow{7}{*}{0.539} & 30 & 122.7 \\
\hline & 40 & 128.3 \\
\hline & 50 & 133.8 \\
\hline & 60 & 142.4 \\
\hline & 70 & 146.6 \\
\hline & 80 & 156.9 \\
\hline & 90 & 165.7 \\
\hline \multirow{7}{*}{0.362} & 30 & 129.7 \\
\hline & 40 & 133.3 \\
\hline & 50 & 138.8 \\
\hline & 60 & 148.0 \\
\hline & 70 & 155.2 \\
\hline & 80 & 157.2 \\
\hline & 90 & 160.8 \\
\hline \multirow{7}{*}{0.189} & 30 & 130.3 \\
\hline & 40 & 138.7 \\
\hline & 50 & 144.4 \\
\hline & 60 & 149.9 \\
\hline & 70 & 157.2 \\
\hline & 80 & 156.7 \\
\hline & 90 & 165.4 \\
\hline
\end{tabular}

theory, and two-state energy model. The adsorption heat involves the initial free gas pressure, and the greater the initial free gas pressure, the less the adsorption heat is.

(2) In the adsorption process at different temperatures, the real-time free gas content increases with time and the adsorption system shows desorption process generally. For the adsorption process with the same initial free gas pressure, the adsorption time increases with the rising temperature. For the adsorption process with different initial free gas pressures at the same temperature, the greater the initial free gas pressure, the shorter the adsorption time it takes to reach an equilibrium state.

\section{Data Availability}

All data included in this study are available upon request from the corresponding author.

\section{Conflicts of Interest}

The authors declare that there are no conflicts of interest regarding the publication of this paper.

\section{Acknowledgments}

Support for this work was provided by the National Natural Science Foundation of China (no. 51704204) and San Jin Scholars Support Plan by Shanxi Province (2016), which is greatly acknowledged by the authors.

\section{References}

[1] T.-t. Cai, Z.-c. Feng, and D. Zhou, "Multi-scale characteristics of coal structure by $\mathrm{x}$-ray computed tomography (X-ray CT), scanning electron microscope (SEM) and mercury intrusion porosimetry (MIP)," AIP Advances, vol. 8, no. 2, p. 025324, 2018.

[2] K. Dong, F. Zeng, J. Jia, C. Chen, and Z. Gong, "Molecular simulation of the preferential adsorption of $\mathrm{CH}_{4}$ and $\mathrm{CO}_{2}$ in middle-rank coal," Molecular Simulation, vol. 45, no. 1, pp. 15-25, 2019.

[3] J. Han, A. K. Bogomolov, E. Y. Makarova et al., "Molecular simulation of $\mathrm{H}_{2} \mathrm{O}, \mathrm{CO}_{2}$, and $\mathrm{CH}_{4}$ adsorption in coal micropores," Russian Journal of Physical Chemistry B, vol. 12, no. 4, pp. 714-724, 2018.

[4] L. Zhang, N. Aziz, T. X. Ren, and Z. Wang, "Influence of temperature on coal sorption characteristics and the theory of coal surface free energy," Procedia Engineering, vol. 26, pp. 1430-1439, 2011.

[5] G. Lu, C. Wei, J. Wang, G. Yan, J. Zhang, and Y. Song, "Methane adsorption characteristics and adsorption modelapplicability of tectonically deformed coals in the Huaibei coalfield," Energy \& Fuels, vol. 32, no. 7, pp. 7485-7496, 2018.

[6] Y. Liu, Y. Zhu, S. Liu, W. Li, and X. Tang, "Temperature effect on gas adsorption capacity in different sized pores of coal: experiment and numerical modeling," Journal of Petroleum Science and Engineering, vol. 165, pp. 821-830, 2018.

[7] Z. Feng, D. Zhao, Y. Zhao, J. Zhao, and Z. Liu, "Effects of temperature and pressure on gas desorption in coal in an enclosed system: a theoretical and experimental study," International Journal of Oil, Gas and Coal Technology, vol. 11, no. 2, pp. 193-203, 2016.

[8] D. Li, Q. Liu, P. Weniger, Y. Gensterblum, A. Busch, and B. M. Krooss, "M High-pressure sorption isotherms and sorption kinetics of $\mathrm{CH}_{4}$ and $\mathrm{CO}_{2}$ on coals," Fuel, vol. 89, no. 3, pp. 569-580, 2010.

[9] D. Zhao, Y. S. Zhao, Z. C. Feng, Z. X. Liu, and T. Liu, "Experiments of methane adsorption on raw coal at 30$270^{\circ} \mathrm{C}$," Energy Sources Part A: Recovery, Utilization and Environment Effects, vol. 34, no. 4, pp. 324-331, 2012.

[10] S. Liu and Z. Meng, "Study on energy variation of different coal-body structure coals in the process of isothermal adsorption," Journal of China Coal Society, vol. 40, no. 6, pp. 1422-1427, 2015.

[11] S. Lu, L. Wang, and L. Qin, "Analysis on adsorption capacity and adsorption thermodynamic characteristics of different 
metamorphic degree coals," Coal Science and Technology, vol. 42, no. 6, pp. 130-150, 2014.

[12] J. Deng, J. Kang, F. Zhou, H. Li, D. Zhang, and G. Li, "The adsorption heat of methane on coal: comparison of theoretical and calorimetric heat and model of heat flow by microcalorimeter," Fuel, vol. 237, pp. 81-90, 2019.

[13] D. D. Do, D. Nicholson, and H. D. Do, "On the Henry constant and isosteric heat at zero loading in gas phase adsorption," Journal of Colloid and Interface Science, vol. 324, no. 1-2, pp. 15-24, 2008.

[14] T. Horikawa, Y. Zeng, D. D. Do, K.-I. Sotowa, and J. R. Alcántara Avila, "On the isosteric heat of adsorption of non-polar and polar fluids on highly graphitized carbon black," Journal of Colloid and Interface Science, vol. 439, pp. 1-6, 2015.

[15] S. H. Madani, S. Sedghi, M. J. Biggs, and P. Pendleton, "Analysis of adsorbate-adsorbate and adsorbate-adsorbent interactions to decode isosteric heats of gas adsorption," ChemPhysChem, vol. 16, no. 18, pp. 3797-3805, 2015.

[16] S. H. Madani, F. Rodríguez-Reinoso, M. J. Biggs, and P. Pendleton, "Isosteric heats of adsorption of gases and vapors on a microporous carbonaceous material," Journal of Chemical \& Engineering Data, vol. 63, no. 8, pp. 3107-3116, 2018.

[17] W. Jiang, Y. Cui, Q. Zhang, and Y. Li, "The quantum chemical study on the coal surface interacting with $\mathrm{CH}_{4}$ and $\mathrm{CO}_{2}$," Journal of China Coal Society, vol. 31, no. 2, pp. 237-240, 2006.

[18] W. Jiang, Y. Cui, Q. Zhang, L. Zhong, and Y. Li, "The quantum chemical study on different rank coals surface interacting with methane," Journal of China Coal Society, vol. 32, no. 3, pp. 292-295, 2007

[19] X. Tang, Z. Wang, N. Ripepi, B. Kang, and G. Yue, “Adsorption affinity of different types of coal: mean isosteric heat of adsorption," Energy \& Fuels, vol. 29, no. 6, pp. 3609-3615, 2015.

[20] L. Zhou, Q. Feng, and Y. Qin, "Thermodynamic analysis of competitive adsorption of $\mathrm{CO}_{2}$ and $\mathrm{CH}_{4}$ on coal matrix," Journal of China Coal Society, vol. 36, no. 8, pp. 1307-1310, 2011.

[21] Z. Liu and F. Zengchao, "Theoretical study on adsorption heat of methane in coal," Journal of China Coal Society, vol. 37, no. 4, pp. 647-653, 2012.

[22] Standardization Administration of the People's Republic of China, Methods of Isothermal Adsorption Experiments of Coal at High Pressures (GB/T19560-2008), Standards Press of China, Beijing, China, 2008.

[23] D. Zhao, T. Cai, D. Zhou, and F. Zengchao, "Isothermal methane adsorption experiments at different temperature stages using the monolayer adsorption principle," Arabian Journal of Geosciences, vol. 11, no. 9, p. 203, 2018.

[24] I. Langmuir, "The Adsorption of gases on plane surfaces of glass mica and platinum," Journal of the American Chemical Society, vol. 40, no. 9, pp. 1361-1403, 1918.

[25] I. Langmuir, "The constitution and fundamental properties of solids and liquids. Part I. Solids," Journal of the American Chemical Society, vol. 38, no. 11, pp. 2221-2295, 1916. 


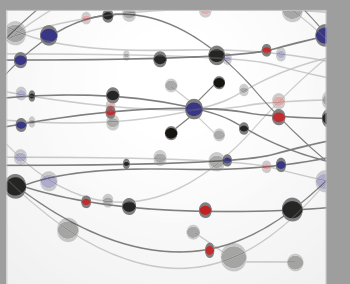

The Scientific World Journal
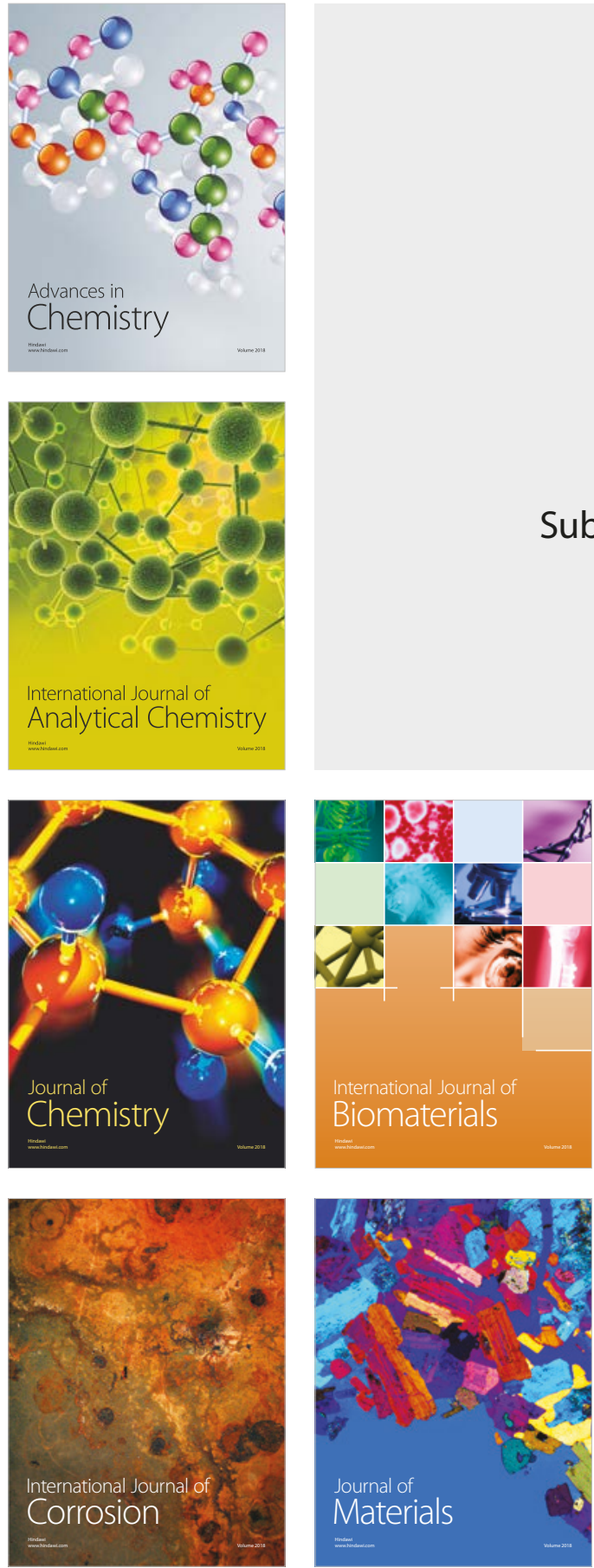

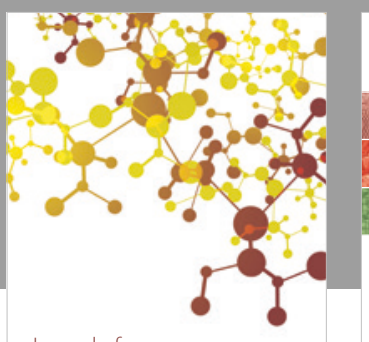

Journal of

Applied Chemistry
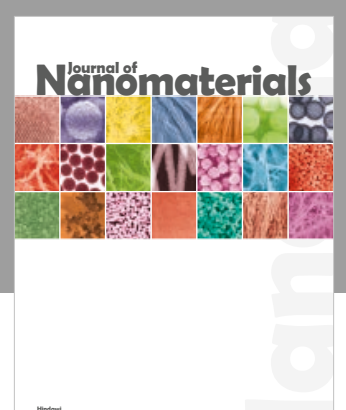

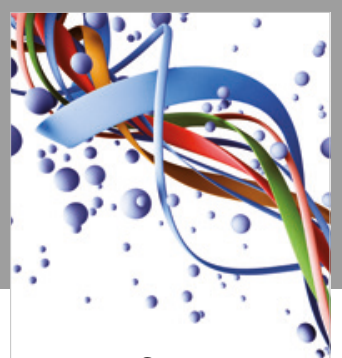

Scientifica

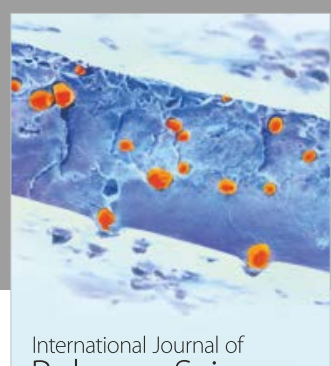

Polymer Science

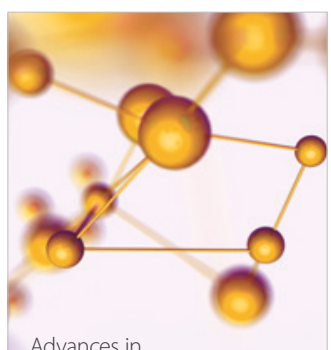

Physical Chemistry
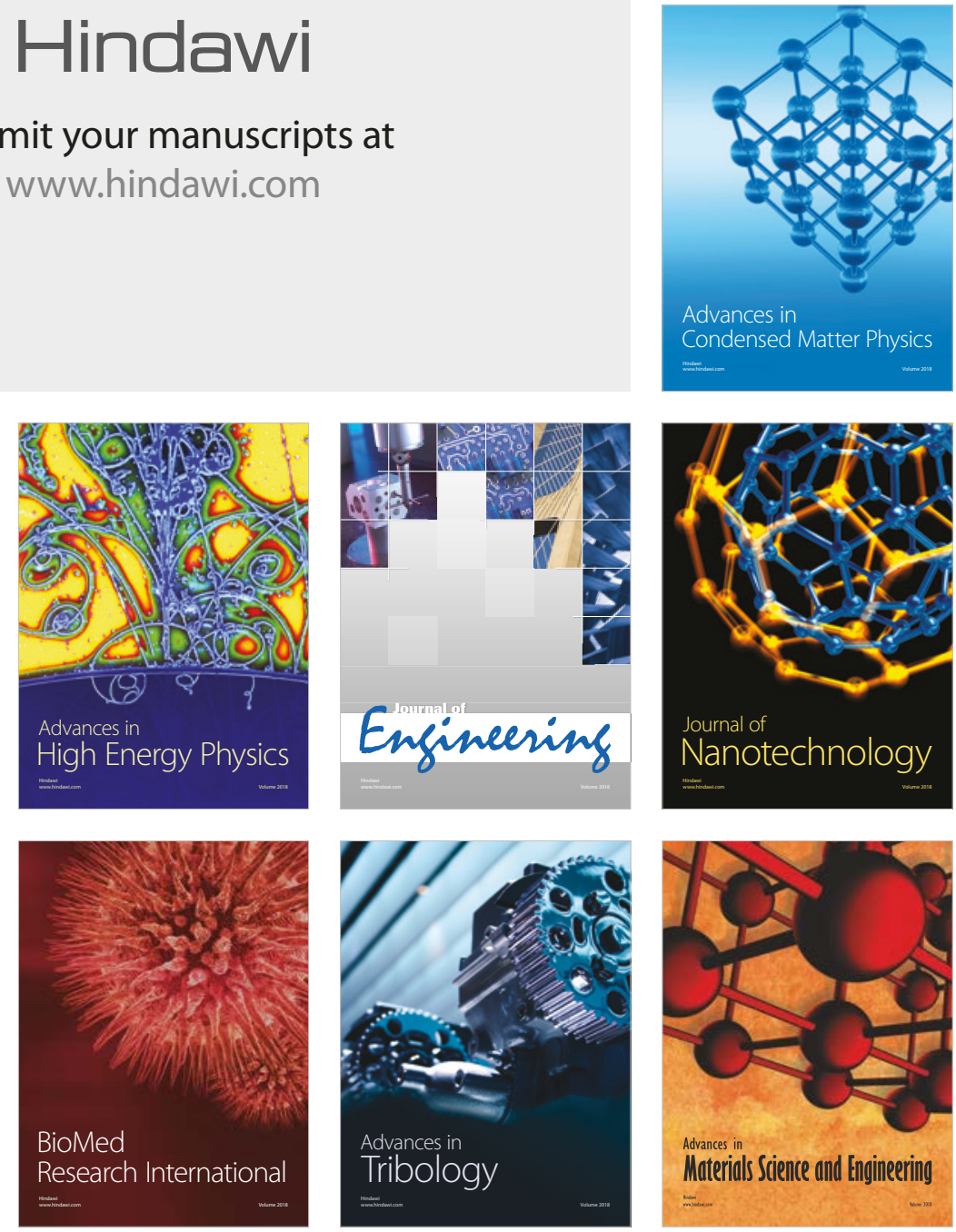